\title{
Sistem Pengairan Otomatis Untuk Tanaman Buah Dalam Pot Berbasis Arduino
}

\author{
Anwar Fu'adi ${ }^{1)}$, Agus Prianggono ${ }^{2)}$ \\ 1) 2) Prodi Pemeliharaan Komputer dan Jaringan AKN Pacitan \\ 1) 2) Jl. Walanda Maramis No. 4A Pacitan \\ 1) anwar@aknpacitan.ac.id, ${ }^{2)}$ agus@aknpacitan.ac.id
}

\begin{abstract}
Abstrak
Teknik menanam tabulampot yakni tanaman buah di dalam pot membutuhkan perhatian ekstra untuk menjaga nutrisi dan kandungan air pada tanah atau media tanam. Pada beberapa kasus, terlewatnya penyiraman tanaman akan membuat tanamana layu, kering, atau mati. Untuk mengatasi hal ini diperlukan teknik penyiraman yang berkerja secara otomatis. Tujuannya adalah agar kandungan air pada media tanam tetap terjaga sehingga tabulampot akan tumbuh dengan subur. Teknik penyiraman secara otomatis diekperimenkan pada penelitian ini mengunakan sebuah board mikrokontroler yakni Arduino dan memanfaatkan sebuah sensor yakni Soil Moisture Censor. Penelitian telah berhasil mensimulasikan sistem pengairan otomatis berbasis arduino dengan menghasilkan prototype yang dapat berjalan dengan baik sesuai dengan skenario yang ditentukan. Prototype berhasil disusun dengan menggunkan empat langkah generik dalam Software Development Lifecycle (SDLC). Fase perancangan dilakukan dengan penyusunan diagram blok. Fase pengembangan dilakukan dengan pembuatan skema rangkaian. Fase instalasi dilakukan dengan merangkai seluruh perangkat sesuai dengan skema rangkaian. Fase pengujian dilakukan dengan menjalankan prototype sesuai dengan skenario yang direncanakan.
\end{abstract}

Kata kunci:tabulampot, arduino, soil moisture sensor, prototype, SDLC

\section{PENDAhuluan}

Lahan pertanian yang semakin sempit memunculkan teknik-teknik menanam yang baru. Beberapa tren menanam yang baru di antaranya teknik hidroponik yang memanfaatkan aliran air nutrisi untuk tanaman, teknik akuaponik yang memanfaatkan limbah teknik akuakultur dari kotoran ikan sebagai nutrisi hidroponik, dan teknik tabulampot yakni menanam buah dalam pot.

Teknik tabulampot memanfaatkan lahan yang sempit untuk menanam tanaman buah kemudian mengatur dan menjaga nutrisinya agar tanaman dapat berbuah dengan baik walaupun ukuran lahan dan ukuran tanaman relatif kecil. Teknik ini menyaratkan perawatan beberapa aspek salah satunya penyiraman yang teratur dengan tetap menjaga kelembaban tanah untuk mengantisipasi penguapan. Hal ini dikarenakan akar tanaman berkembang di media yang sangat sempit yakni pot, sehingga kadar air harus selalu dijaga.

Salah satu kendala adalah jika pemilik tabulampot terlewat menyirami tanaman maka tanaman akan layu, kering, bahkan mati. Untuk mengantisipasi hal ini perlu diimplementasikan suatu sistem yang dapat menyirami tabulampot secara otomatis berdasarkan kondisi tanah atau media tempat tambulapot ditanam.

Tujuan penelitian ini adalah mengembangkan dan mengimplementasikan sistem pengairan otomatis berbasis Arduino untuk perkebunan tabulampot. Manfaat dari penelitian ini adalah terjaganya kondisi kandungan air dalam tanah atau media tempat tanam tabulampot untuk menghindari tanaman layu, kering, dan mati.

\section{METODE PENELITIAN}

Penelitian ini menggunakan metode analisis qualitatif action research, data yang diperlukan dalam penelitian ini diperoleh melalui observasi langsung terhadap proses kerja yang dilaksanakan. Penelitian ini dilaksanakan pada bulan Oktober 2020.

Peneliti memulai tahapan penelitian dengan menyusun diagram blok yang menggambarkan bagaimana seluruh perangkat akan dipasang. Diagram blok dibawah ini 
menggambarkan gabungan dari sistem kelistrikan dan sistem irigasi. Sistem kelistrikan menggunakan pembangkit listrik tenaga surya. Sistem irigasi otomatis menggunakan pompa yang tersambung ke relay dan dikontrol oleh arduino.

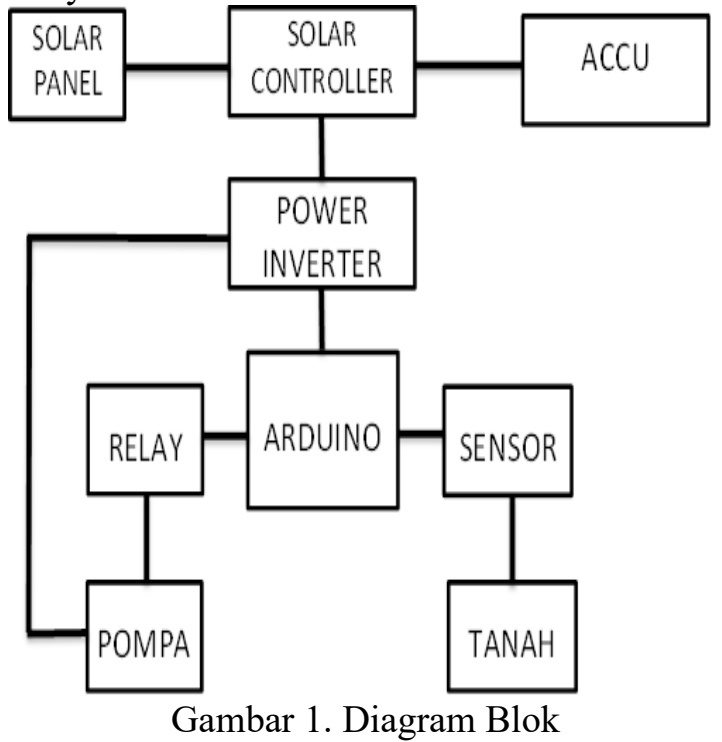

Berdasarkan diagram blok di atas, peneliti membagi perancangan ke dalam empat bagian sebagai berikut:

a. Skema rangkaian LCD dengan arduino

b. Skema rangkaian Soil Moisture Sensor dengan arduino

c. Skema rangkaian Relay $5 \mathrm{~V}$ dengan arduino

d. Skema rangkaian Pembangkit listrik tenaga surya

\section{a. Skema Rangkaian LCD}

LCD digunakan untuk menampikan hasil pengukuran kondisi kelembaban tanah yang dilakukan oleh arduino dengan menggunakan soil moisture sensor. LCD yang digunakan adalah LCD yang dapat bekerja dengan Hitachi HD44780 driver (Arduino.cc, 2020). LCD ini memiliki 16 pin dengan skema rangkaian sebagai berikut:

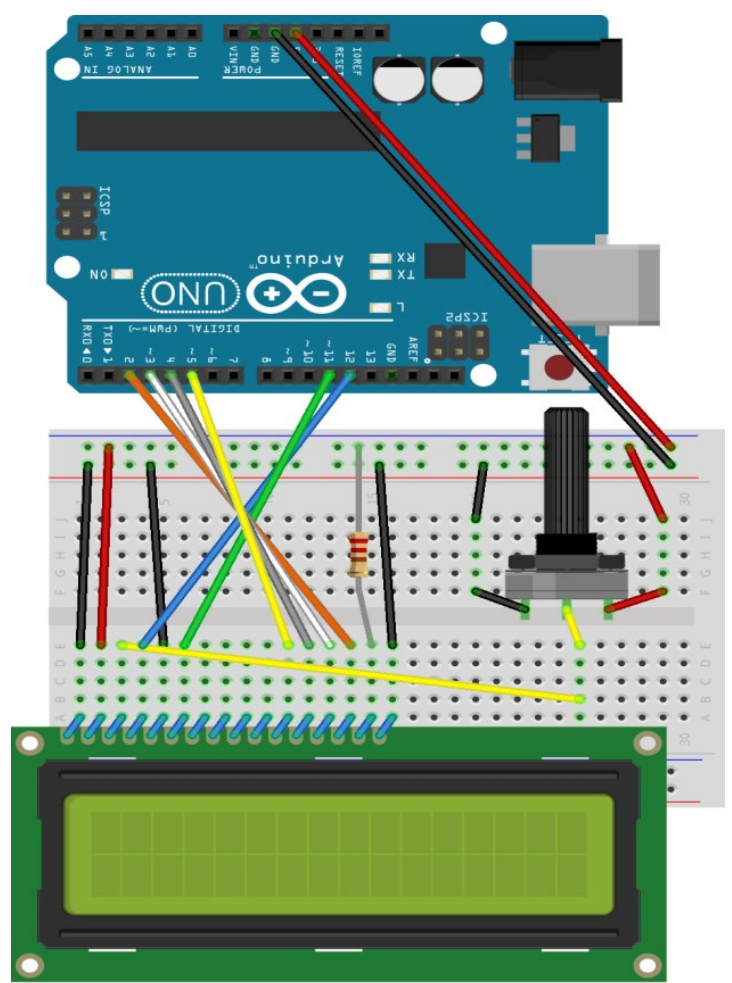

Gambar 2. LCD dengan 16 PIN

\section{b. Skema Rangkaian Soil Moisture Sensor}

Soil moisture sensor memiliki 2 bagian utama yakni sensor dan komparator. Sensor akan mengukur kondutifitas tanah yang dikonversi dalam sinyal analog dan digambarkan dengan angka 0-1023. Angka ini dapat diklasifikan kedalam golongan tanah kering, lembab, dan basah. Sensor benilai 0339 berarti basah. Sensor bernilai 340-475 berarti lembab, 476-1023 berarti kering (Husdi, 2018).

Rangkaian sensor, komparator, dan arduino disusun sebagai berikut:

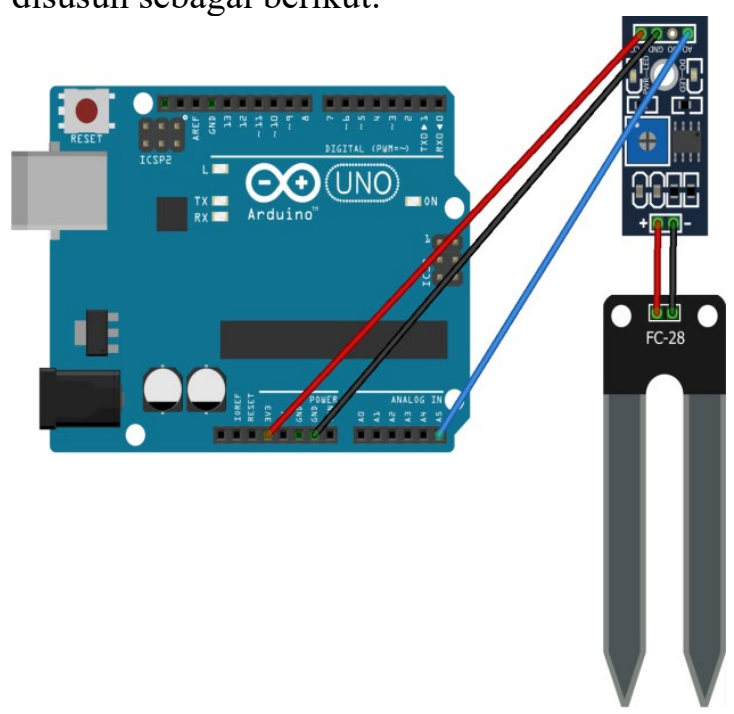

Gambar 3. Skema Rangkaian Soil Moisture Sensor 


\section{c. Skema Rangkaian Relay $\mathbf{5 V}$}

Relay 5V seperti SRD-05VDC-SL-C memiliki tiga terminal bertegangan tinggi dengan arus AC yakni Normally Closed (NC), Normally Open (NO) dan Common Terminal (C). Pada sisi lain dari relay terdapat tiga pin bertegangan rendah yakni Ground, VCC, dan Signal. Relay 5V dirangkai dengan arduino sebagai berikut:

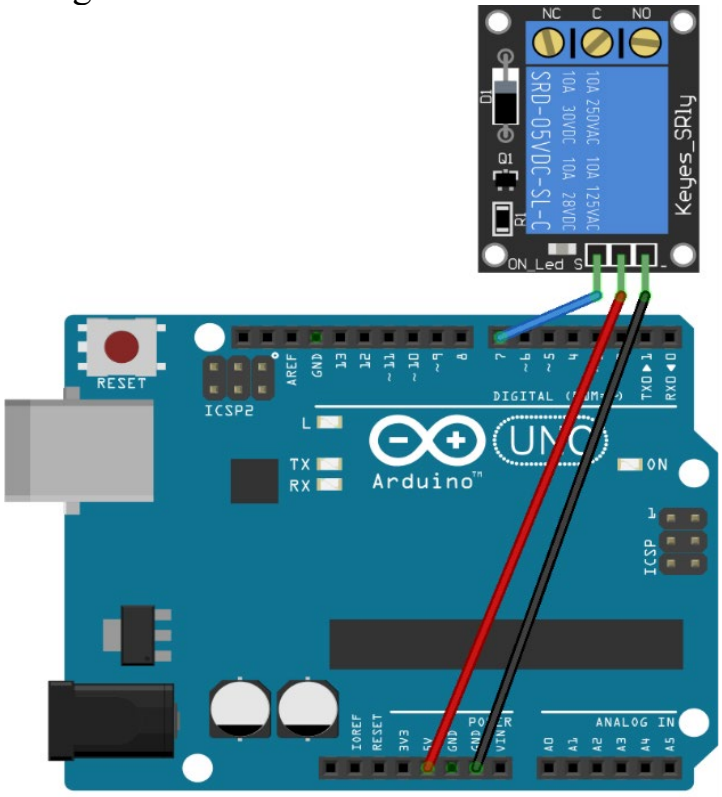

Gambar 3. Skema Rangkaian Relay 5V

\section{d. Skema Rangkaian Solar System}

Untuk keperluan sumber listrik, penelitian ini menggunakan sumber tenaga listrik dari PLTS dengan menggunakan rangkaian seperti di bawah ini. Panel surya menyerap tenaga matahari untuk dikonversi menjadi tegangan arus DC disalurkan ke solar controller. Solar controller mengatur arus DC yang diterima dengan disalurkan ke baterai untuk disimpan dan menyalurkan ke inverter untuk diubah menjadi listrik AC bertegangan 220 Volt.

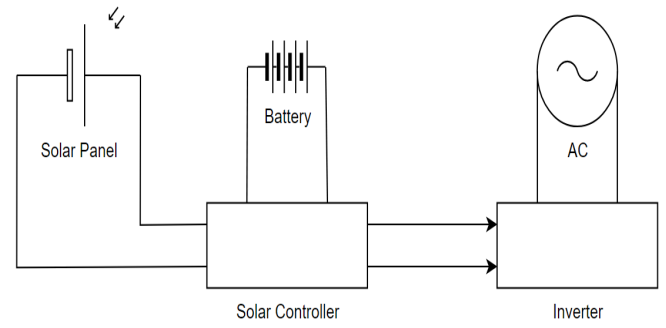

Gambar 4. Skema Rangkaian Solar System

\section{TINJAUAN PUSTAKA}

Metode budidaya tanaman buah dalam pot (tabulampot) dibuat untuk menjawab tantangan keterbatasan lahan. Tabulampot adalah kepanjangan dari tanaman tumbuh dalam pot yang memiliki arti yaitu tumbuhan yang dibudidayakan didalam pot yang tujuannya yaitu untuk hiasan ataupun untuk di produksi buahnya. Dalam dunia akademisi tabulampot ialah teknologi budidaya tanaman dengan memanfaatkan ruangan yang terbatas untuk dapat menumbuhkan tanaman yang produktif didalam pot (Kementerian Pertanian, 2020).

Perawatan pada tabulampot meliputi penyiraman, penyiangan, pemangkasan dahan dan akar, pemupukan, pengendalian hama dan penyakit, serta penggantian media tanam dan pot. Penyiraman merupakan perawatan yang paling penting. Tanaman akan mati karena layu dan kering jika penyiraman tidak dilakukan dengan tepat.

Arduino adalah kit elektronik atau papan rangkaian elektronik open source yang di dalamnya terdapat komponen utama yaitu sebuah chip mikrokontroler dengan jenis AVR dari perusahaan Atmel. Mikrokontroler adalah chip atau IC (integrated circuit) yang bisa diprogram menggunakan komputer. Tujuan menanamkan program pada mikrokontroler adalah agar rangkaian elektronik dapat membaca input, memproses input tersebut dan kemudian menghasilkan output sesuai yang diinginkan. Jadi mikrokontroler bertugas sebagai otak yang mengendalikan input, proses dan output sebuah rangkaian elektronik (I. Efendi, 2020).

Kegunaan Arduino tergantung kepada kita yang membuat program. Arduino bisa digunakan untuk mengontrol LED, bisa juga digunakan untuk mengontrol helikopter. Bahasa pemrograman Arduino adalah bahasa C. Bahasa ini sudah dipermudah menggunakan fungsi-fungsi yang sederhana sehingga pemula pun bisa mempelajarinya dengan cukup mudah.

Soil Moisture Sensor mengukur kandungan air dalam tanah. Pengukuran kandungan air secara gravimetri membutuhkan proses pembersihan, pengeringan, dan penimbangan yang rumit, sehingga Soil Moisture Sensor akan mengukur kandungan air dalam tanah secara tidak langsung berdasarkan beberapa karakteristik tanah diantaranya electrical resistance, 
dielectric constant, dan neutrons interaction. Relasi antara karakteristik yang diukur dengan kondisi kandungan air secara langsung harus dikalibrasi dan hansilnya akan sangat tergantung beberapa factor diantaranya jenis tanah, suhu, dan kondutifitas tanah (Algorista, 2020).

Software Development Lifecycle SDLC merupakan serangkaian tahapan yang dibutuhkan dalam pengembangan suatu sistem, yang dimulai dari investigasi dan analisis kebutuhan dasar, desain, implementasi, dan pemeliharaan (R.S. Pressman, 2015).

Berdasarkan tinjauan pustaka, dalam penelitian ini peneliti mengembangkan sekaligus mengimplementasikan sistem pengairan otomatis berbasis arduino dengan sensor kandungan air dalam tanah (Soil Moisture Sensor ) mengunakan tahapan pengembangan sistem SDLC.

\section{HASIL DAN PEMBAHASAN}

Berdasarkan rancangan tahapan kegiatan yang telah disusun, selanjutnya dilaksanakan tahap implementasi sesuai dengan rancangan pada diagram blok.

Tahap pertama adalah menyusun rangkaian solar sistem yang terdiri dari solar panel, inverter dan baterai. Rangkaian solar sistem dapat dirangkai seperti pada gambar 5., gambar 6. dan gambar 7. berikut :

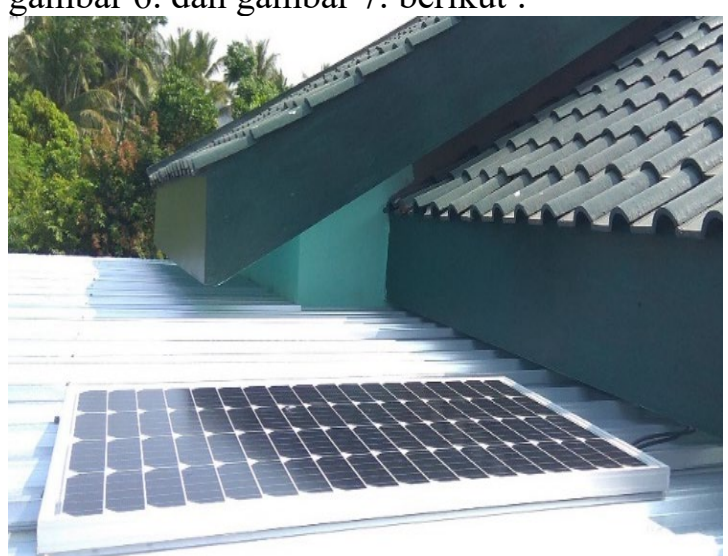

Gambar 5. Solar Panel
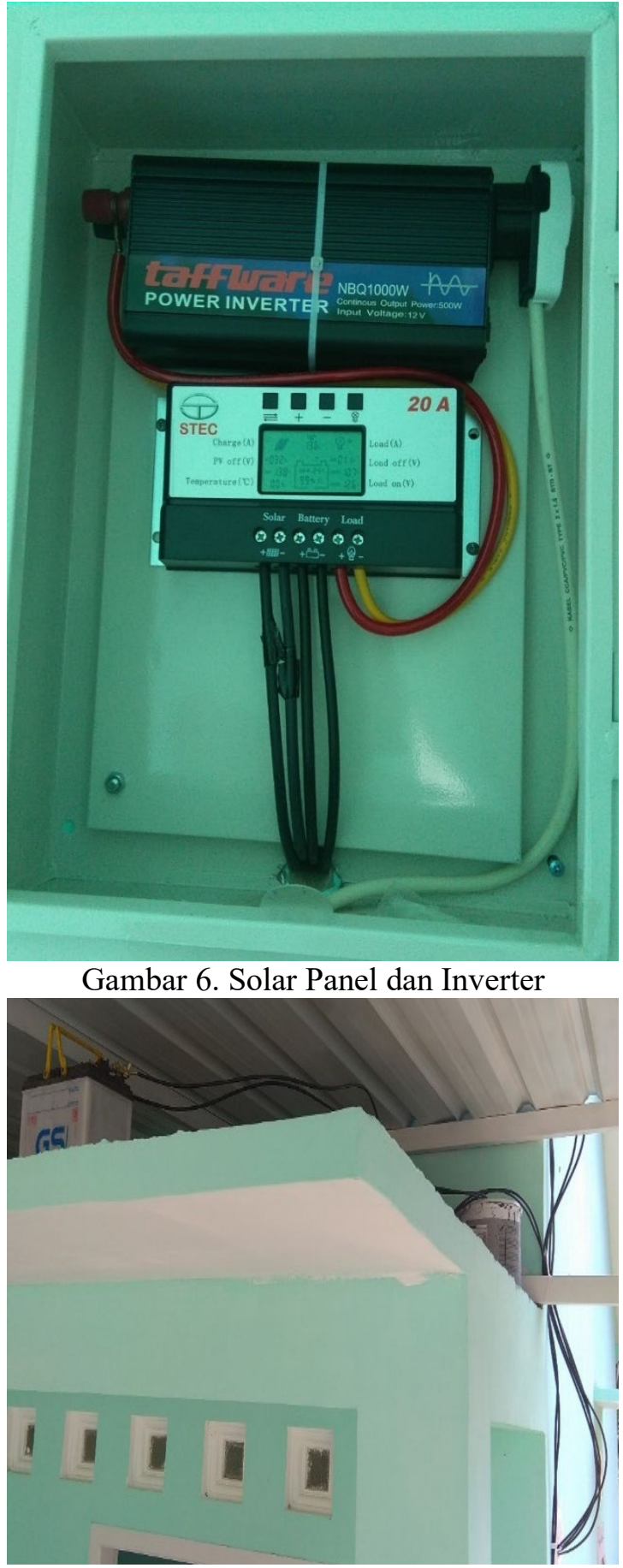

Gambar 7. Baterai

Selanjutnya menyusun rangkaian arduino, relay $5 \mathrm{~V}$, dan soil moisture sensor seperti pada gambar 8 . berikut : 


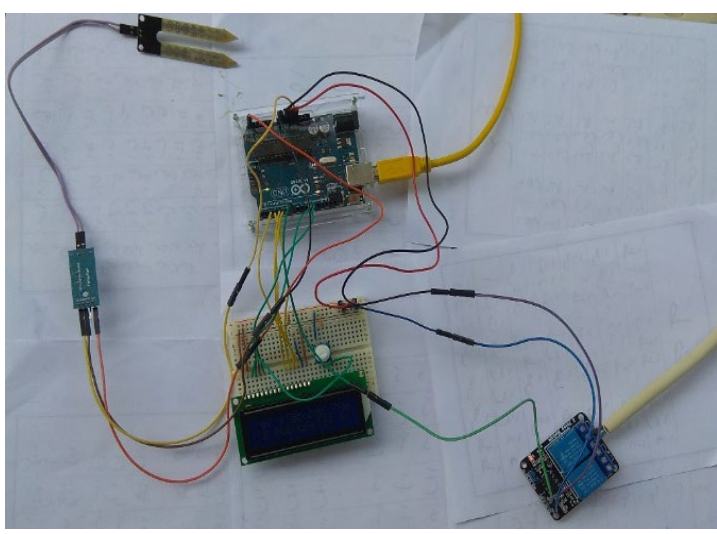

Gambar 8. Rangkaian Arduino, Soil Moisture Sensor, dan Relay 5V

Selanjutnya dilakukan pengkodean sketch arduino. Kode program yang ditulis pada sketch arduino dapat dijelaskan sebagai berikut:

Tabel 1. Penjelasan Kode Program

\begin{tabular}{cl}
\hline Baris & \multicolumn{1}{c}{ Penjelasan } \\
\hline 1 & $\begin{array}{l}\text { Memanggil library LiquidCrystal.h } \\
\text { untuk mengontrol LCD }\end{array}$ \\
2 & $\begin{array}{l}\text { Mendefinisikan LCD agar } \\
\text { memanfaatkan pin nomor 12,11, 5, }\end{array}$ \\
4 & $\begin{array}{l}\text { M, 3, dan 2 } \\
\text { Mendefinisikan pin analog untuk } \\
\text { mengambil nilai sensor melalui pin }\end{array}$ \\
5 & A5 \\
& $\begin{array}{l}\text { Mendefinisikan pin 7 sebagai pin } \\
\text { untuk mengontrol relay }\end{array}$ \\
9 & $\begin{array}{l}\text { Mendefinisikan dimensi LCD yang } \\
\text { digunakan 16 kolom 2 baris }\end{array}$ \\
10 & $\begin{array}{l}\text { Mendefinisikan pin 7 untuk } \\
\text { mengontrol relay beroperasi } \\
\text { sebagai output }\end{array}$ \\
15 & $\begin{array}{l}\text { Membaca nilai dari soil moisture } \\
\text { sensor }\end{array}$ \\
18 & $\begin{array}{l}\text { Menyalakan relay jika nilai soil } \\
\text { moisture sensor lebih dari 500 }\end{array}$ \\
19 & $\begin{array}{l}\text { Mematikan relay jika nilai soil } \\
\text { moisture sensor kurang dari 100 }\end{array}$ \\
$23-$ & Menampilkan informasi ke LCD \\
29 & \\
\hline
\end{tabular}

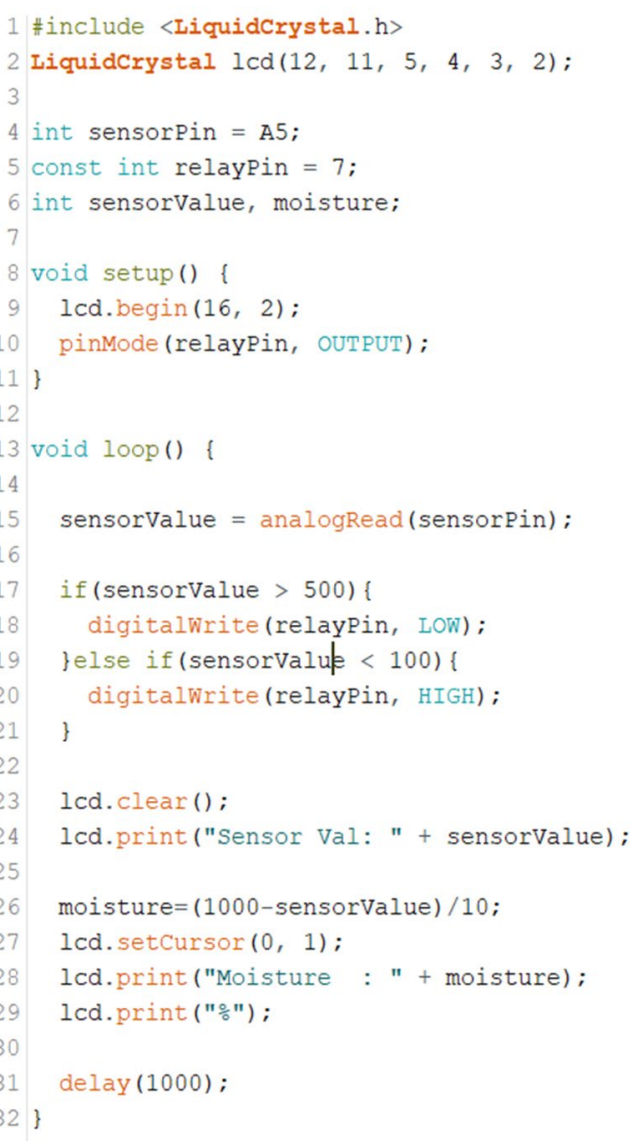

Gambar 9. Kode Progam pada Arduino

Selanjutnya dilakuan pengujian dengan skenario sebagai berikut:

- Solar panel mendapat sinar matahari

- Solar Controller menerima arus listrik DC

- Solar Controller menyalurkan arus listrik DC ke baterai

- Solar Controller menyalurkan arus listrik DC ke power inverter

- Power inverter menghasilkan listrik AC untuk arduino dan pompa

- Soil moisture sensor mengukur tanah kering, relay menyala dan pompa mengalirkan air

- Soil moisture sensor mengukur tanah basah, relay mati dan pompa berhenti mengalirkan air

- LCD menampilkan informasi nilai sensor dan persentase kelembaban tanah

Berdasarkan hasil pengujian yang dilakukan, diperoleh hasil bahwa rangkaian prototype yang dibuat dapat berfungsi sebagaimana direncanakan. Hasil pengujian prototype dapat dilihat pada gambar berikut : 

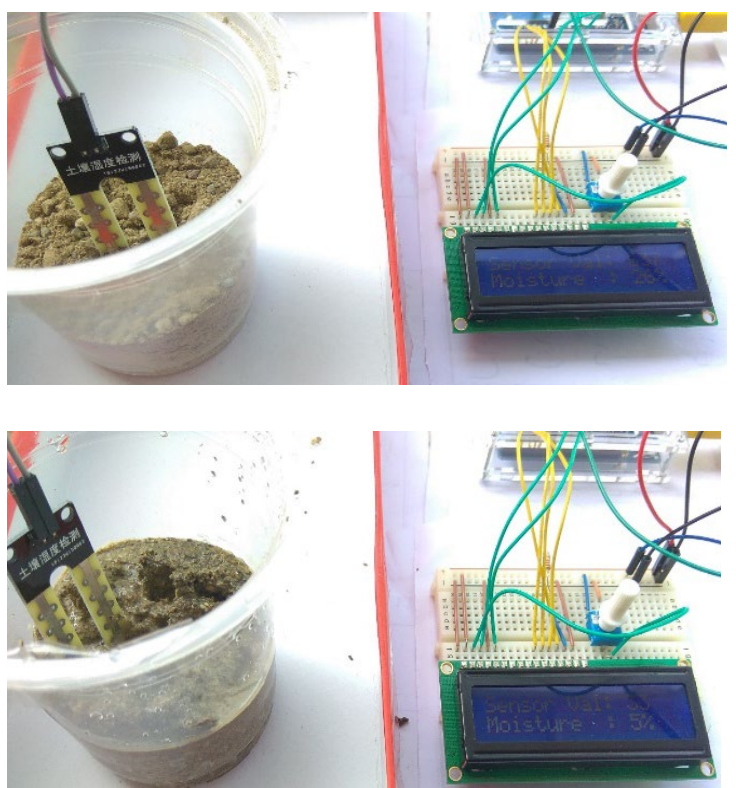

Gambar 10. Pengujian Smart Watering System

\section{KESIMPULAN DAN SARAN \\ a. Kesimpulan}

Penelitian telah berhasil mensimulasikan sistem pengairan otomatis berbasis arduino dengan menghasilkan prototype yang dapat berjalan dengan baik sesuai dengan skenario yang ditentukan. Prototype berhasil disusun dengan menggunkan empat langkah generik dalam SDLC. Fase perancangan dilakukan dengan penyusunan diagram blok. Fase pengembangan dilakukan dengan pembuatan skema rangkaian. Fase instalasi dilakukan dengan merangkai seluruh perangka sesuai dengan skema rangkaian. Fase pengujian dilakukan dengan menjalankan prototype sesuai dengan skenario yang direncanakan.

Peneliti mengucapkan terima kasih kepada semua pihak yang bekontribusi terhadap penelitian ini. Peneliti membuka diri untuk menerima saran dan masukan dari semua pihak demi penyempurnaan penelitian ini.

\section{b. Saran}

Saran peneliti dalam rangka pengembangan untuk memperbaiki lanjutan penelitian ini agar dapat diimplementasikan dengan lebih baik yaitu bahwa sistem yang dikembangkan saat ini masih sangat sederhana sehingga membutuhkan pengembangan yang cukup signifikan, mungkin kedepan bisa menambahkan jenis sensor lain yang lebih lengkap sehingga sistem ini lebih akurat dan fleksibel.

\section{REFERENSI}

Kementrian Pertanian, "Cara Mudah Membuat Tabulampot," [Accessed 1409-2020]. [Online]. Available : http://cybex.pertanian.go.id/mobile/artike 1/80212/CARA-MUDAH-MEMBUATTABULAMPOT-Tanaman-Buah-DalamPot/

I. Efendi, "Pengertian dan Kelebihan Arduino," [Online]. Available: https://www.it-jurnal.com/pengertiandan-kelebihan-arduino/. [Accessed 09 Oktober 2020].

Algorista, "Sensor Kelembaban Tanah atau Soil Moisture," [Online]. Available: http://www.algorista.com/2020/01/sensor -soil-moisture.htm. [Accessed 09 Oktober 2020].

R. S. Pressman.(2015).Software Engineering: A Practitioner's Approach, New York: McGraw-Hill Education,.

Arduino.cc, "'Hello World!"," [Online]. Available: https://www.arduino.cc/en/ Tutorial/LibraryExamples/HelloWorld. [Accessed 0910 2020].

M. Y. J. B. M Mediawan, "Automatic Watering System in Plant House," 3rd Annual Applied Science and Engineering Conference, p. 434, 2018.

Dwijaya Kesuma, Ida Bagus; Sudarma, Made; Alit Swamardika, Ida Bagus.(2018). Rancang Bangun Sistem Pengaman Berbasis Arduino Uno. Jurnal SPEKTRUM, [S.1.], Vol. 3, No. 2, p. 8992,

Husdi, H. (2018). Monitoring Kelembaban Tanah Pertanian Menggunakan Soil Moisture Sensor Fc-28 Dan Arduino Uno. ILKOM Jurnal Ilmiah, 10(2), 237243. Doi : https://doi.org/10.33096/ ilkom.v10i2.315.237-243

Wulantika Sintia, Dedy Hamdani, Eko Risdianto. (2018). Rancang Bangun Sistem Monitoring Kelembaban Tanah dan Suhu Udara Berbasis GSM SIM900A Dan Arduino Uno. Jurnal Kumparan Fisika, Vol.1, No.2, p. 60-65. 